\title{
FORMAÇÃO CONTINUADA PARA PROFESSORES NO PACTO NACIONAL PELA ALFABETIZAÇÃO: CONTINUIDADES, RUPTURAS E RESSIGNIFICAÇÕES
}

\author{
Maria Aparecida Lapa de Aguiar ${ }^{T}$ \\ Caren Cristina Brichi $i^{2}$ \\ Soraia Irrigaray Zapata ${ }^{3 *}$
}

\begin{abstract}
RESUMO: As reflexôes presentes neste trabalho são decorrentes de pesquisas que se centraram na análise de relatórios de Orientadores de Estudo (OEs) que atuaram no Pacto Nacional pela Alfabetização na Idade Certa (PNAIC) em Santa Catarina. Refletir sobre a formação do alfabetizador no Brasil ainda se constitui como uma demanda necessária e atual, com questôes que acompanham essa temática há muitos anos: como alfabetizar? Que variáveis precisam ser consideradas? Quem é a criança das escolas públicas? O que pode favorecer a formação do alfabetizador e contribuir para o processo de escolarização das crianças?
\end{abstract}

Palavras-chave: PNAIC. Orientadores de Estudo. Alfabetização.

\footnotetext{
${ }^{1}$ Universidade Federal de Santa Catarina, Departamento de Estudos Especializados em Educação, Centro de Ciências da Educação - Florianópolis (SC), Brasil. E-mail: cida.aguiar@gmail.com

${ }^{2}$ Universidade Federal de Santa Catarina, Programa de Pós-Graduação em Educação, Centro de Ciências da Educação - Florianópolis (SC), Brasil. E-mail: carenbrichi@gmail.com

${ }^{3}$ Universidade Federal de Santa Catarina, Curso de Pedagogia, Centro de Ciências da Educação - Florianópolis (SC), Brasil. E-mail: soraiairrigaray@gmail.com *Bolsista do Programa Institucional de Bolsas de Iniciação Científica (UFSC/CED/ Pedagogia/PIBIC).

DOI: 10.1590/CC0101-32622017173656
} 


\title{
Continued Education for teachers in the National Literacy Pact: continuities, ruptures and resignifications
}

\begin{abstract}
The insights present in this work are a product of researches centered on the analyses of reports written by Study Advisors who took part in the National Literacy at the Right Age Pact (Pacto Nacional pela Alfabetização na Idade Certa PNAIC) in Santa Catarina. Reflecting about the education of literacy teachers in Brazil is still a necessary and current issue. These are the questions that have come with it for many years now: how should we teach literacy? What variables need to be considered? Who is the public school child? What factors can support the literacy teacher and contribute to the child's schooling process?
\end{abstract}

Keywords: PNAIC. Study Advisors. Literacy.

\section{INTRODUÇÃO}

Mais uma vez contempla a palavra escrita na estrada. Ao lado, volta a escrivinhar. Lhe vem uma outra palavra, sem cuidar na escolha: "LUZ". Dá um passo atrás e examina a obra. Então pensa: "a cor azul tem o nome certo. Porque tem as iguais letras da palavra 'luz', fosse o seu feminino às avessas”. De súbito, lhe chegam sons distantes no tempo, semelhando gritos de meninagem em recreio. $\mathrm{O}$ menino estremece: aquela era uma primeira lembrança. (COUTO, 2007, p. 37)

A

$s$ reflexóes presentes neste trabalho são decorrentes de estudos e investigaçóes ${ }^{1}$ desenvolvidas pelas autoras a partir da inserção em um dos Núcleos de Pesquisa do Centro de Ciências da Educação da Universidade Federal de Santa Catarina (UFSC) ${ }^{2}$.

Refletir sobre a formação de professores alfabetizadores no Brasil ainda se constitui como uma demanda necessária e atual, com questóes que acompanham essa temática há muitos anos: como alfabeti- 
zar? Por onde começar? Que variáveis precisam ser consideradas? O que ensinar? Quem é a criança das escolas públicas? Que formação recebe o professor que atuará no ciclo alfabetizador? Que concepçóes balizam essas práticas? O que pode favorecer a formação do alfabetizador e contribuir para o processo de escolarização das crianças?

Já é fato e se põe como jargão de políticos, economistas, empresários e senso comum a defesa de que toda criança tem direito à educaçáo, mas qual é exatamente o tipo de educação que se deseja para os filhos dos trabalhadores, que são, em sua maioria, os que frequentam nossas escolas públicas? Quem são esses sujeitos? O que eles já sabem? O que podemos e devemos lhes ensinar? O que podemos aprender com eles? Como a instituição escola, lugar de ensinar e aprender, contribui (ou não) para que a formação humana em sua plenitude e potencialidade tenha seu desenvolvimento assegurado? Quais são as condiçóes reais (profissionais/pessoais) dos professores/trabalhadores da educação?

Essas perguntas e outras tantas estiveram permeando a formação oferecida pelo Pacto Nacional pela Alfabetização na Idade Certa $(\mathrm{PNAIC})^{3}$ e vem acompanhando pesquisas em geral ${ }^{4}$ referentes ao próprio PNAIC e corroboram, de certa forma, para a defesa do direito principal de toda criança em processo de escolaridade: o direito de aprender.

Tais perguntas não se esgotam neste texto, tampouco pretendemos respondê-las; elas se colocam como norteadoras de nossas buscas e de nossa pretensa intenção de contribuir para essa necessária reflexão sobre a formação continuada do alfabetizador.

O objetivo geral da pesquisa é analisar relatórios dos Orientadores de Estudo $(\mathrm{OE})^{5}$ do PNAIC na intenção de verificar, a partir de uma amostragem, como se configurou a formação desse programa nas redes de ensino de Santa Catarina. Trata-se de uma pesquisa de caráter documental, tendo como fonte de dados os relatórios dos OEs. Para este artigo, especificamente, apresentaremos um recorte com a análise de um relatório, averiguando continuidades, rupturas e ressignificaçóes da própria formação oferecida.

Para tanto, organizamos esta explanação da seguinte forma: primeiramente, apresentamos essas questóes iniciais e nosso ponto 
de partida, para depois tecer algumas reflexóes sobre o PNAIC e o significado desse programa de formação no contexto de Santa Catarina. Traremos alguns pressupostos teóricos e, por fim, apresentaremos alguns indícios já encontrados na pesquisa em andamento relacionados à formação de professores no PNAIC presentes nos relatórios dos OEs.

\section{O PACTO PELA ALFABETIZAÇÃO EM SANTA CATARINA}

O programa de formação continuada, instituído pelo governo federal, denominado PNAIC, foi assumido por um dos núcleos de pesquisa do Centro de Ciências da Educação (CED) da UFSC, iniciou-se em 2013 e atendeu praticamente todos os municípios do estado. Essa formação atingiu cerca de 8.000 alfabetizadores, comportando uma equipe de coordenadores, formadores e OEs que atuaram em quatro polos de formação em 2013 (três no litoral e um no Oeste catarinense) e em cinco polos em 2014 e 2015 (três no litoral e dois na região oeste).

Os relatórios pesquisados dizem respeito ao polo 2: Joinville e região, relativos ao ano de 2013, com cerca de 53 municípios envolvidos e aproximadamente 120 OEs. Em 2013, tínhamos quatro formadores de Língua Portuguesa e, em 2014, cinco formadores de Língua Portuguesa e cinco de Matemática.

Para essa formação continuada, a equipe responsável adotou o registro por meio de relatórios realizados pelos OEs. Tais relatórios eram entregues aos formadores bimestralmente e arquivados na universidade.

O parâmetro para essa formação eram os cadernos disponibilizados pelo Ministério da Educação, além de outros materiais, como explicitado a seguir:

- $\quad$ livros didáticos (entregues pelo Programa Nacional do Livro Didático - PNLD) e respectivos manuais do professor; 
- obras pedagógicas complementares aos livros didáticos e acervos de dicionários de Língua Portuguesa (também distribuídos pelo PNLD);

- jogos pedagógicos de apoio à alfabetização;

- $\quad$ obras de referência, de literatura e de pesquisa (entregues pelo Programa Nacional de Biblioteca Escolar - PNBE);

- $\quad$ obras de apoio pedagógico aos professores;

- $\quad$ jogos e softwares de apoio à alfabetização. (BRASIL, 2012)

Os cadernos de formação com os quais a pesquisa se relaciona dizem respeito à área de Língua Portuguesa e abordaram temáticas, divididas em unidades, conforme apresenta o Quadro 1 na página seguinte.

A realidade com a qual nos deparamos em relação aos municípios que fazem parte do PNAIC em Santa Catarina é bastante diversa. Há municípios com populaçáo pequena, em torno de 1.400 habitantes, e há aqueles que chegam a cerca de 500.000 habitantes. Algumas cidades possuem histórico e cultura de formação continuada há muitos anos, enquanto outras estão estreando nesse tipo de imersão de estudos e debates. Assim, o que constituiu o polo que escolhemos para análise, bem como os demais, foi a heterogeneidade que gerou conflitos e também muitos ganhos pelas trocas e aprendizagem que se fizeram ao longo do processo formativo.

De antemão, afirmamos que essa formação continuada não traz novas questóes, todavia, as indagaçóes provocadas continuam necessárias para a discussão sobre a alfabetização na atualidade: como acolher a criança que chega aos seis anos de idade no Ensino Fundamental? Como o currículo precisa ser organizado? Como pensar na integração das várias áreas do conhecimento? Como não esquecer que a criança continua sendo criança nos anos iniciais do Ensino Fundamental? Como proporcionar uma metodologia que dê conta da ludicidade, do brincar, do aprender brincando, da especificidade de ser criança? Como organizar formas de avaliação desse processo em prol do desenvolvimento das potencialidades humanas? 


\section{Quadro 1}

\section{Unidades do Pacto Nacional pela}

\section{Alfabetização na Idade Certa e suas ementas.}

\begin{tabular}{|c|c|}
\hline Unidade 1 & $\begin{array}{l}\text { Concepções de alfabetização; currículo no ciclo de alfabetização; inter- } \\
\text { disciplinaridade; avaliação da alfabetizaçáo; inclusáo como princípio } \\
\text { fundamental do processo educativo. }\end{array}$ \\
\hline Unidade 2 & $\begin{array}{l}\text { Planejamento do ensino na alfabetização; rotina da alfabetização na } \\
\text { perspectiva do letramento, integrando diferentes componentes curricu- } \\
\text { lares (Matemática, Ciências, História, Geografia, Arte); a importância } \\
\text { de diferentes recursos didáticos na alfabetização: livros de literatura do } \\
\text { PNBE e PNBE Especial, livro didático aprovado no PNLD, obras } \\
\text { complementares distribuídas no PNLD, jogos distribuídos pelo MEC, } \\
\text { jornais, materiais publicitários, televisão, computador, entre outros. }\end{array}$ \\
\hline Unidade 3 & $\begin{array}{l}\text { Funcionamento do Sistema de Escrita Alfabética; reflexão sobre os pro- } \\
\text { cessos de apropriaçáo do Sistema de Escrita Alfabética e suas relaçóes com } \\
\text { a consciência fonológica; planejamento de situaçóes didáticas destinadas } \\
\text { ao ensino do Sistema de Escrita Alfabética. }\end{array}$ \\
\hline Unid & $\begin{array}{l}\text { Sala de aula como ambiente alfabetizador: exposição e organização de } \\
\text { materiais que favorecem o trabalho com a alfabetizaçáo; diferentes agru- } \\
\text { pamentos em sala de aula; atividades diversificadas em sala de aula para } \\
\text { atendimento às diferentes necessidades das crianças: jogos e brincadeiras } \\
\text { no processo de apropriaçáo do Sistema de Escrita Alfabética e sistema nu- } \\
\text { mérico decimal; atividades em grande grupo para aprendizagens diversas: } \\
\text { exploraçáo da literatura como atividade permanente; estratégias de inclu- } \\
\text { sáo de crianças com deficiência visual, auditiva, motora e intelectual, bem } \\
\text { como crianças com distúrbios de aprendizagem nas atividades planejadas. }\end{array}$ \\
\hline Unic & $\begin{array}{l}\text { Diferentes textos em salas de alfabetização: textos de tradição oral; textos } \\
\text { que ajudam a organizar o dia a dia; os textos do jornal; as cartas e os } \\
\text { textos dos gibis. }\end{array}$ \\
\hline Unidade 6 & $\begin{array}{l}\text { Projetos didáticos e sequências didáticas na alfabetização, integrando } \\
\text { diferentes componentes curriculares (Matemática, Ciências, História, } \\
\text { Geografia, Arte); o papel da oralidade, da leitura e da escrita na apropria- } \\
\text { çáo de conhecimentos de diferentes áreas do saber escolar. }\end{array}$ \\
\hline Unidade 7 & $\begin{array}{l}\text { Avaliação; planejamento de estratégias de atendimento das crianças que } \\
\text { não estejam progredindo conforme as definiçóes dos conceitos e das ha- } \\
\text { bilidades a serem dominados pelas crianças (direitos de aprendizagem); } \\
\text { inclusão das crianças com dificuldades de aprendizagem e crianças com } \\
\text { necessidades educacionais especiais. }\end{array}$ \\
\hline Unidad & $\begin{array}{l}\text { Avaliação final; registro de aprendizagens; direitos de aprendizagem; } \\
\text { avaliação do trabalho docente; organização de arquivos para uso no coti- } \\
\text { diano da sala de aula. }\end{array}$ \\
\hline
\end{tabular}

Fonte: Adaptação do quadro presente no caderno de Apresentação (BRASIL, 2012, p. 32). 


\section{PRESSUPOSTOS TEÓRICOS PARA A PESQUISA}

Nossa perspectiva teórica está embasada em autores filiados à abordagem histórico-cultural que concebem a mediação e a interação como processos fundantes para o ensino e a aprendizagem, a linguagem como interação humana e a escola como um espaço possível e legitimado de sistematização de conhecimentos.

Vygotski $^{6}$ (1995) e tantos outros a partir dele pontuam que a linguagem é interação humana, ou seja, se somos seres sociais, nascemos em um mundo imerso em possibilidades de linguagem (gestos, balbucios, choros, gritos, desenhos, escritas, símbolos vão sendo significados pelos outros seres humanos que nos rodeiam e que já estavam no mundo antes de nós chegarmos).

Estamos imersos em um caldo cultural que se abre para diversos tipos de manifestação de linguagem e a criança que está conosco na escola e nas instituições de educação infantil também se encontra inserida nesse contexto complexo e intenso. Então, a linguagem é social desde sua essência; ela nos constitui e nós a constituímos ao longo da história humana (BAKHTIN, 1995).

A criança nasce mergulhada em um mundo que lhe oferece possibilidades diversas de linguagem e ela tem o direito de acesso a essa diversidade. Por isso, recorremos a Luria (1988, p. 27) para refletirmos sobre essas questóes da linguagem e sua complexificação ao longo processo humano:

Desde o nascimento, as crianças estáo em constante interação com os adultos, que ativamente procuram incorporá-las à sua cultura e à reserva de significados e de modos de fazer as coisas que se acumulam historicamente. No começo, as respostas que as crianças dáo ao mundo são dominadas pelos processos naturais, especialmente aqueles proporcionados por sua herança biológica. Mas através da constante mediação dos adultos, processos psicológicos instrumentais mais complexos começam a tomar forma. 
O processo de humanização vai se dando nessa interação e os processos naturais vão se complexificando e formando as funçôes psicológicas superiores (controle consciente do comportamento, atençáo voluntária, pensamento abstrato, capacidade de planejamento, memória lógica, formação de conceitos) (VYGOTSKI, 1995).

Ao se pensar na escola como o lugar legitimado de sistematização do conhecimento e, portanto, como o espaço por excelência do aprendizado da leitura e escrita, corroboramos com as reflexóes feitas por Mello (2009) baseadas em Vygotsky:

Retomando Vygotsky e suas contribuições para o processo de apresentação da escrita à criança de modo que a escrita se torne um instrumento de expressão e conhecimento do mundo para uma criança leitora e produtora de textos, vale destacar as diretrizes apontadas por ele: 1 . que o ensino da escrita se apresente de modo que a criança sinta necessidade dela; 2 . que a escrita seja apresentada não como um ato motor, mas como uma atividade cultural complexa; 3 . que a necessidade de aprender a escrever seja natural, da mesma forma como a necessidade de falar; 4. que ensinemos às crianças a linguagem escrita e não as letras. (MELLO, 2009, p. 35)

Diante da perspectiva apontada por Vygotski (1995), Luria (1988) e Bakhtin (1995), e reafirmada nas palavras de Mello (2009), recorremos ainda a Smolka (1989) que desde a década de 1980 já conceituava a alfabetização sob esse mesmo ponto de vista:

[...] a alfabetização não implica, obviamente, apenas a aprendizagem da escrita de letras, palavras e oraçôes. Nem tampouco envolve apenas uma relação da criança com a escrita. A alfabetização implica, desde a sua gênese, a constituição do sentido. Desse modo, implica mais profundamente, uma forma de interação com o outro pelo trabalho de escritura - para quem eu escrevo o que escrevo e por quê? A criança pode escrever para si mesma, palavras soltas, tipo lista, para não es- 
quecer; tipo repertório, para organizar o que já sabe. Pode escrever, ou tentar escrever um texto, mesmo fragmentado, para registrar, narrar, dizer... Mas essa escrita precisa ser sempre permeada por um sentido, por um desejo, e implica ou pressupóe, sempre, um interlocutor. (SMOLKA, 1989, p. 69)

Soares (2004), considerada uma das grandes referências nos estudos da alfabetização, apresenta os conceitos de alfabetização e letramento como distintos, porém indissociáveis. A autora faz essa distinção em razão de questôes muito específicas que vêm ocorrendo no cenário brasileiro e que ela considera bastante preocupante: faz-se necessário reconhecer a especificidade do sistema de escrita alfabética, sua organização, pois é preciso um processo de sistematização, mas, ao mesmo tempo, necessita-se que esse processo ocorra em contextos de letramento. Ou seja, não é um retorno a métodos já bastante criticados, mas é uma proposta de partir de gêneros discursivos que circulam socialmente para que realmente faça sentido para a criança e com elas ir estabelecendo relaçóes sobre o funcionamento da língua escrita.

A formação do PNAIC se aproxima dessa abordagem, orientando o trabalho pedagógico para a alfabetização em uma perspectiva de letramento, o que implica uma concepção de imersão na cultura escrita, que provoque situaçóes em que esta se faça presente e necessária.

\section{CONTINUIDADES, RUPTURAS E RESSIGNIFICAÇÕES: INDÍCIOS SOBRE A FORMAÇÃO DO PNAIC}

A fonte de dados sob a qual lançamos nosso olhar investigativo, como dito anteriormente, foi uma amostragem dos relatórios desenvolvidos em 2013 por cerca de 120 OEs que compuseram o polo 2 (Joinville e região). Ressaltamos novamente que tais municípios eram díspares em vários aspectos: número de habitantes, peculiaridades culturais e trajetória de formação continuada. Assim, encontramos 
nos relatórios da amostragem aspectos divergentes e convergentes que apontam para continuidades, rupturas e ressignificaçóes próprias de um processo formativo. Para este artigo, a título de ilustração, escolhemos um desses relatórios e procuraremos a seguir detalhá-lo e tecer algumas análises, procurando refletir sobre aspectos que podem favorecer a formação do alfabetizador e contribuir para o processo de escolarização das crianças.

\section{RELATÓRIO DE UM DOS ORIENTADORES DE ESTUDO DO PNAIC: DESCRIÇÃO E ANÁLISE ${ }^{7}$}

RELATÓRIO 3 (ABRIL/MAIO DE 2013) /

FORMADORA 3 / OE: 3 (BLUMENAU-SC)

O foco do relatório desenvolvido por uma das OEs da rede estadual com os professores alfabetizadores no município de Blumenau-SC foi o conceito de avaliação na alfabetização e seus instrumentos, tendo como base a Provinha Brasil. Os encaminhamentos se deram a partir dos cadernos da Unidade 1 da formação do PNAIC.

A OE registra que orientou os professores para comparar as questôes da Provinha Brasil com os Direitos de Aprendizagem de Língua Portuguesa. Ela descreve também reflexôes que foram sistematizadas com as professoras e que elencamos a seguir:

- Avaliação em sua dimensão formativa, diagnóstica, processual, descritiva, qualitativa.

- $\quad$ Progressão continuada equivocadamente tomada como progressão automática.

- Instrumentos de observação e registro (portfólios).

- Dimensóes conceituais (aprender a aprender), procedimentais (aprender a fazer) e atitudinais (aprender a viver e ser).

- Agrupamentos diferenciados de crianças em momentos distintos do processo de aprendizagem. 
Nesse encontro, a OE menciona que também foram trabalhados os objetivos presentes no Caderno 2 da mesma Unidade 1 que contemplam: concepçóes de alfabetização, recursos didáticos distribuídos pelo Ministério da Educação (MEC), planejamento e importância da literatura. Também realizaram a leitura dos conceitos da Unidade 2 - Ano 2: planejamento no ciclo de alfabetização objetivos e estratégias para o ensino relativo ao componente curricular Língua Portuguesa; e como atividade a distância: rotinas de alfabetização na perspectiva do letramento. A organização do processo de ensino e de aprendizagem e a direção dos trabalhos se pautaram em: planejar para quê? Por quê? Como? Foi também incluída nesse mesmo encontro uma atividade a distância de leitura do primeiro texto da Unidade 3 - A compreensão do Sistema de Escrita Alfabética e a consolidação da alfabetização.

Nos anexos desse relatório aparecem os slides usados na formação, fotos das professoras em grupos de estudo, fotos de atividades desenvolvidas em relação aos direitos de aprendizagem e os eixos da Língua Portuguesa. Há também uma fotocópia da Provinha Brasil, comentários sobre as questôes da prova e o que esta abordava, além de um quadro comparativo entre questôes da prova e os direitos de aprendizagem. Há ainda a atividade desenvolvida em grupo pelas professoras, que consistia em identificar nas questóes os direitos contemplados e, por fim, o quadro da rotina da semana.

$\mathrm{Na}$ segunda parte do relatório, relacionada aos encontros realizados em maio, a formadora apresenta uma prática que era comum na formação ocorrida nos polos e que ela reproduz em seu município com as professoras alfabetizadoras: o uso de mensagens e vídeos para reflexão e motivação. Esses encaminhamentos eram combinados no planejamento entre formadoras e OEs. Percebe-se que as OEs, de modo geral, seguiam essa direção, que se constituía como uma marca presente nos encaminhamentos dos cadernos de formação que orientavam no sentido de que os encontros fossem iniciados com leitura deleite, vídeo e reflexão. A coordenação do PNAIC na UFSC, quando organizava a formação, incentivava essa mesma orientação. Assim, um banco de dados enorme foi se construindo em cada polo de formação, com muitas trocas de vídeos, planejamentos e materiais 
pedagógicos entre os pares. O que se percebeu foi que as OEs passaram a usar a tecnologia abundantemente, como e-mails, blogs e redes sociais, ferramentas de acesso compartilhado com as quais as formadoras e orientadoras iam alimentando esse banco de dados coletivo. Pode-se afirmar que isso ocorria concomitantemente a um processo de letramento digital.

A OE cita também em seu relatório que trabalhou os objetivos presentes no caderno do Ano 2 da Unidade 3 e que foram discutidos e complementados pelo vídeo Alfabetização - apropriação do sistema de escrita alfabética, ${ }^{8}$ conforme orientaçáo do planejamento da formadora com o grupo de OEs. $\mathrm{O}$ que também se visualiza nesse relatório são depoimentos que retratam como estavam as crianças em relação às hipóteses da escrita, a partir da Perspectiva Psicogenética de Ferreiro, mesmo que a equipe de formação da universidade fizesse críticas a esses encaminhamentos presentes nos cadernos do PNAIC.

A OE também faz referência aos materiais disponíveis na escola para o processo de alfabetização, como jogos, livros (PNBE) e obras complementares que muito contribuíam para o fazer pedagógico.

Ainda no relatório, a $\mathrm{OE}$ comenta sobre o diário de bordo em que as professoras registravam o encaminhamento da formação. Era uma combinação advinda da coordenação do PNAIC na universidade, que se constituía em uma metodologia de registro e retomada das discussóes realizadas. A cada encontro, uma professora ficava responsável pelo registro e no encontro seguinte lia suas anotaçóes para as colegas. Esse diário de bordo tinha a função de ser a memória do grupo e o fio condutor de um encontro para o outro, favorecendo retomadas e compreensóes sobre o processo formativo.

Em síntese, a OE demonstra que seu trabalho com os professores alfabetizadores esteve em concordância com as orientações recebidas na formação e com os pressupostos do PNAIC de refletir sobre o Sistema de Escrita Alfabética na perspectiva do letramento. Também foram citados no relatório outros aspectos contemplados na formação dos OEs, como a discussão em torno dos Direitos de Aprendizagem em Língua Portuguesa. Entretanto, a OE direcionou seu trabalho estabelecendo a relação desses direitos com a Provinha 
Brasil, que não estava prevista no encaminhamento da formação organizada pela universidade. Precisamos levar em conta que essa avaliação externa tem se incorporado à dinâmica de nossas salas de aula e que, de certa forma, tem influenciado nas decisóes curriculares e nos encaminhamentos de sala de aula e, por isso, merecem uma reflexão.

Não temos dúvida de que é preciso avaliar e essa função é constitutiva de nosso metier, mas, de um tempo para cá, essa atribuição não cabe somente a nós; ela se transfigura em uma regulação do Estado sobre nós, em uma tentativa de controle sobre o estudante e sobre o professor - esse fato é inegável e há de nos alertar. A quem essas avaliaçóes externas estão a serviço? O que dizem seus resultados sobre o nosso trabalho pedagógico com as crianças? Como lidar homogeneamente com grupos de crianças espalhadas pelo Brasil em regióes, escolas, redes distintas, condiçóes socioeconômicas díspares e que se constituem pela heterogeneidade?

O PNAIC traz em seu bojo uma concepção de alfabetização que vem ao encontro de muitas discussôes que estâo entre nós educadores desde, pelo menos, a década de 1980, presentes em pesquisas e estudos no âmbito acadêmico e que também vimos refletidas em propostas curriculares, nos Parâmetros Curriculares Nacionais e em outros documentos oficiais, que defendem a linguagem como interação humana, a importância da mediação pedagógica e da escuta das crianças envolvidas no processo. Entáo, como lidar com essa contradição que, muitas vezes, uma avaliação padronizada nos impóe?

Fica evidente nesse relatório que as orientações dessa formação dadas pela $\mathrm{OE}$ às suas professoras demonstram a tentativa de questionar os processos avaliativos, quando problematizam os tipos de avaliação, os processos formativos das crianças em suas especificidades balizadas pelas concepçôes do próprio PNAIC. Porém, essas professoras estão inseridas em um sistema e não têm como negá-lo, por isso procuram dar respostas "positivas" a ele, preocupando e ocupando-se de questôes relacionadas às avaliaçóes externas, porque sabem que os resultados desses processos avaliativos recaem sobre elas, sobre a escola e sobre as crianças. 
Esse relatório, portanto, apresenta continuidades no que diz respeito a questóes que não são novas na educação, que continuam merecendo nossas reflexóes e que constituem o fazer do professor: planejar, organizar metodologicamente os processos de ensino e aprendizagem e avaliar. A concepção trazida pelo PNAIC a respeito desses aspectos vem na esteira do que já se tem apontado em geral no âmbito acadêmico (nas pesquisas, nos cursos de formação inicial) e na formação continuada desde a década de 1980, como já pontuamos, concepção esta pautada em um processo de alfabetização que considere as crianças em suas singularidades, como sujeitos de direito - entre eles, o direito de aprender.

Não percebemos, pelo menos nesse relatório, algum tipo de ruptura mais abrupta com o que foi orientado a ser desenvolvido pelo programa de formação em questão, mas se evidenciam algumas ressignificaçóes. O relatório escolhido para a análise faz um trabalho bastante reflexivo sobre a Provinha Brasil, o que demonstra preocupação e compromisso dessa rede com as expectativas postas por essas avaliaçóes externas, mesmo que ainda se constitua um ponto nodal que não vai necessariamente nos dizer muito sobre a verdadeira aprendizagem dessas crianças.

Outro aspecto que merece destaque é a sobreposição explícita nos cadernos do PNAIC de perspectivas teóricas distintas como a abordagem histórico-cultural (com referência a Vygotsky) e a construtivista de base piagetiana (na qual se ancoram os estudos de Ferreiro e Teberosky) e que aparecem também refletidas nas descriçóes do trabalho presente no relatório analisado.

É importante mencionar que essa característica de mesclar as duas perspectivas está presente também nos Parâmetros Curriculares Nacionais e podemos ainda inferir que algumas propostas curriculares assim também se caracterizam. Como os professores alfabetizadores, em seus processos formativos, vão traduzindo para o campo da prática pedagógica as concepçóes presentes em arcabouços teóricos que apresentam convergências e divergências? Essa formação do PNAIC se efetiva nas práticas de sala de aula no movimento do agir desses sujeitos históricos e singulares que se apropriam dos conhecimentos da formação, reproduzindo, transformando, deformando, ressig- 
nificando a partir do confronto com formaçóes anteriores (inicial, continuada), na relação com seu contexto e com as possibilidades que lhe são postas pela rede de ensino em que estão inseridos, pelas escolas e pelas crianças.

\section{CONSIDERAÇÕES FINAIS}

As indagações postas no decorrer deste artigo sobre a necessidade de acolher essa criança que chega aos seis anos de idade no Ensino Fundamental, com reflexôes sobre quem são esses sujeitos da escola pública, como o currículo deve ser pensado, como as metodologias e os processos avaliativos interferem nas questóes de ensino e aprendizagem, estiveram no cerne das orientaçóes que compuseram o repertório da formação dos professores alfabetizadores no PNAIC e que, de certa forma, aparecem referenciadas nos relatórios dos OEs. Portanto, essa política de formação continuada contribuiu para que o professor pudesse tomar consciência de que mesmo que a criança de seis anos não esteja mais no seu papel de sujeito da educação infantil e passe a ser o sujeito do processo de escolarização, não perde, por isso, seu status de ser criança e todo o ciclo de alfabetização merece ser repensado sob essa ótica.

A formação do PNAIC pode não ter se constituído como "novidade”, pois, afinal, além das temáticas e concepções já serem conhecidas, muitas redes de ensino já vinham propiciando momentos de reflexão teoria/prática com seus professores em perspectivas semelhantes às desse programa de formaçáo. Entretanto, pela heterogeneidade encontrada no Estado de Santa Catarina (acreditamos que não deva ser diferente em outros estados da Federação), essa formação contribuiu para mobilizar redes de ensino pela abrangência atingida e pelas trocas proporcionadas nos polos de formação. Com certeza, os processos de aprendizagem desencadeados não são nem foram os mesmos, afinal, estamos lidando com sujeitos em formação (crianças e professores) e, por mais que qualquer tipo de formação possa ter a intenção de algum controle sobre as consequências do processo, seria ingenuidade não considerar que tais formaçôes se constituem em sua história pelas continuidades, rupturas e ressignificaçóes. 
Para finalizar, deixamos outras questóes a se pensar em relação à formação continuada de professores: que percurso já realizamos até aqui? Por onde continuar? Como assegurar o direito das crianças de aprender e o direito dos professores a uma formação continuada que lhes dê as condiçóes de ensinar a todas as crianças? Cada professor tem sua história de formação (inicial e continuada) e cada criança tem sua história de vida (familiar, cultural), então, como entrelaçar esses seres e suas histórias no processo de ensinar e aprender? Como as teorias e reflexóes que vêm se constituindo ao longo da história no campo educacional nos ajudam a ler a nós mesmos e as crianças a nossa volta? Quais políticas públicas necessitamos para concretizar a utopia de uma escola para todas as crianças e, principalmente, para aquelas que sofrem as contradições dessa sociedade desigual e tão injusta, que resistem e insistem em acreditar na escola como uma possibilidade para a vida?

\section{REFERÊNCIAS}

BAKHTIN, M. Marxismo e filosofia da linguagem. 7a. ed. São Paulo: Hucitec, 1995.

BRASIL. Ministério da Educação. Secretaria de Educação Básica. Diretoria de Apoio à Gestão Educacional. Pacto Nacional pela Alfabetização na Idade Certa: Formação do professor alfabetizador: Caderno de Apresentação. Brasília: MEC/ SEB, 2012.

COUTO, Mia. Terra sonâmbula. São Paulo: Companhia das Letras, 2007.

LURIA, A.R. O desenvolvimento da escrita na criança. In: VIGOTSKI, L.S.; LURIA, A.R.; LEONTIEV, A.N. Linguagem, desenvolvimento e aprendizagem. 4a. ed. São Paulo: Ícone, 1988.

MELLO, S.A. O processo de aquisição da escrita na educação infantil: contribuiçôes de Vygotsky. In: FARIA, A.L.G.; MELLO, S.A. (Orgs.). Linguagens infantis: outras formas de leitura. $2^{\mathrm{a}}$. ed. Campinas, SP: Autores Associados, 2009. p. 21-36.

SMOLKA, A.L.B. A criança na fase inicial da escrita: a alfabetização como processo discursivo. $2^{\text {a }}$. ed. Campinas, SP: Cortez, 1989. 
SOARES, M. Letramento e alfabetização: as muitas facetas. Revista Brasileira de Educação, Rio de Janeiro, n. 25, abr. 2004. Disponível em: <http://www. scielo.br/scielo.php?script $=$ sci arttext\&pid $=$ S1413-24782004000100002\&

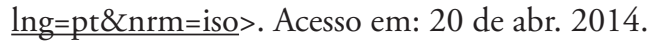

VYGOTSKI, L.S. Obras Escogidas III (incluye problemas del desarrollo de la psique). Madrid: Visor, 1995.

\section{NOTAS}

1. A pesquisa em andamento intitulada "A formação de professores no Pacto Nacional pela Alfabetização na Idade Certa - PNAIC - 2013: Consideraçóes a Partir de Relatórios dos Orientadores de Estudo" (2015/2017) desencadeou outras duas pesquisas: a dissertação em andamento da mestranda e o Trabalho de Conclusão de Curso da bolsista PIBIC.

2. Núcleo de Estudos e Pesquisa em Alfabetização e Ensino da Língua Portuguesa NEPALP (CED/UFSC), responsável pelo programa do governo federal de formação de professores alfabetizadores no Estado de Santa Catarina/Brasil: PNAIC. Cabe ressaltar que tanto a professora quanto a mestranda estiveram diretamente envolvidas com o PNAIC em Santa Catarina, fazendo parte da equipe responsável por essa formação.

3. Desse momento em diante usaremos somente a sigla: PNAIC.

4. A título de ilustração, citamos a dissertação ainda em andamento de uma das autoras deste artigo (Caren Cristina Brichi), que fez o levantamento no banco de teses e dissertaçôes da Coordenação de Aperfeiçoamento de Pessoal de Nível Superior (Capes) no período de 2013-2016 e encontrou 130 produçóes a partir do descritor PNAIC.

5. Essa é a designação de um dos perfis que constituía o quadro dos integrantes do PNAIC. Tratam-se de professores ligados às redes de ensino atuantes em salas de aula ou em Secretarias de Educação, com experiência na alfabetização de crianças e que se responsabilizaram pela formação de alfabetizadores em seus municípios. A partir de agora utilizaremos a sigla $\mathrm{OE}$ sempre que nos referirmos ao Orientador de Estudo e OEs para seu plural.

6. As autoras mantém no texto a grafia do nome de Vigotski de acordo com as referências.

7. Estabelecemos a seguinte convenção: os relatórios, os formadores e os OEs receberam uma numeração conforme tabelas organizadas em arquivo pelo grupo de pesquisa. Assim, o analisado nesse artigo corresponde ao relatório 3; em seguida vem o mês e ano correspondente. As formadoras também receberam uma numeração de 1 a 4 conforme convenção estabelecida naquele ano de formação, pois tínhamos quatro formadoras no polo e cada qual atuava em uma turma. No caso do relatório aqui 
analisado, a formadora atuava na turma 3. O OE foi numerado também como 3, conforme a ordem estabelecida em nosso banco de dados, e colocamos ainda a referência ao município onde atuava.

8. O vídeo citado aparece como sugestáo no Caderno Ano 2, Unidade 3 do PNAIC e remete ao site da Universidade Federal de Pernambuco (UFPE) e ao Centro de Estudos em Educação e Linguagem (CEEL), responsável pela organização do material utilizado na formação do PNAIC: "Alfabetização: apropriação do Sistema de Escrita Alfabética” (disponível em <http://www.ufpe.br/ceel>).

Recebido em 14 de janeiro de 2017. Aprovado em 24 de junho de 2017. 